\title{
Identifikasi Keberadaan Organic Shale Berdasarkan Analisis Data Magnetotellurik Pada Cekungan Kutai
}

\author{
Rainerius Rodriguez Sidharta dan Yatini \\ Jurusan Teknik Geofisika, UPN “Veteran” Yogyakarta, Jalan Ring Road Utara \\ SWK 104 Condong Catur 55283. Indonesia
}

*Penulis Penanggungjawab E-mail : rainerius.sidharta@gmail.com

\begin{abstract}
ABSTRAK
Kebutuhan akan gas dan minyak bumi dunia terus meningkat seiring berjalannya waktu. Salah satu kebijakan pemerintah Indonesia adalah meningkatkan eksplorasi dan produksi cadangan minyak dan gas bumi nonkonvensional seperti shale oil dan shale gas. Metode Magnetotelurik (MT) digunakan dalam penelitian ini dikarenakan keterbatasan penetrasi kedalaman oleh Metode Seismik yang disebabkan oleh batugamping yang sangat tebal sebagai low velocity layer sehingga sulit bagi gelombang mekanik untuk menembus lapisan tersebut. Penelitian mencari bagaimana cara melakukan pengolahan dan interpretasi data MT menggunakan software SSMT2000, MTEditor dan WINGLINK pada daerah telitian untuk menghasilkan model organic shale yang baik. Proses pematangan thermal organic content yang terkandung dalam shale mulai terjadi pada kedalaman 2500 hingga 9500 dan persebarannya relatif kearah barat daya - timur laut. Pada kedalaman 10500 belum dapat diinterpretasikan sebagai organic shale dikarenakan proses crosspower hanya sampai dengan frekuensi $0,01 \mathrm{~Hz}$.
\end{abstract}

Kata Kunci : Serpih organik; magnetotellutik; resistivitas 


\begin{abstract}
The world's gas and petroleum needs continue to increase over time. One of the Indonesian government's policies is to increase sales and non-conventional petroleum such as shale oil and shale gas. Magnetoteluric (MT) method used in this research is as the penetration limit of seismic measurement caused by such a low velocity layer. This research aims to find how to do the processing and interpretation of MT data using SSMT2000, MTEditor and WINGLINK software on the research area to produce a good organic shale model. The process of maturation of the thermal organic content contained in the shale begins to occur at depths of 2500 to 9500 and its distribution towards the relative southwest northeast. At a depth of 10500 can not be interpreted as organic shale because the crosspower process is only up to a frequency of $0.01 \mathrm{~Hz}$. Where the smaller the frequency is the greater the depth will be.
\end{abstract}

Keywords : Organic shale; magnetotelluric; resistivity

\section{Pendahuluan}

Kebutuhan akan gas dan minyak bumi dunia terus meningkat seiring berjalannya waktu, Indonesia mengalami peningkatan jumlah populasi dari tahun ke tahun, dimana telah membuat Indonesia menjadi negara dengan penduduk terbanyak ke-4 di dunia. Peningkatan jumlah penduduk tersebut, sesuai dengan peningkatan kebutuhan akan energi konvensional. Peningkatan penyediaan energi adalah minimal $1.25 \%-1.3 \%$ lebih besar dari pertumbuhan ekonomi. Akan tetapi, ketersediaan energi yang ada di Indonesia tidak sepadan dengan jumlah populasi yang terus meningkat, dimana pada tahun 2012, terdapat peningkatan populasi sebesar $6.2 \%$ dengan hanya peningkatan penyediaan energi pada Total Primary
Energy Supply (TPES) sebesar 3.15\% [1].

Salah satu kebijakan pemerintah Indonesia adalah meningkatkan eksplorasi dan produksi cadangan minyak dan gas bumi non-konvensional seperti shale oil dan shale gas agar mendapatkan cadangan minyak dan gas bumi dalam jumlah yang besar. Sebagi contoh shale gas adalah gas yang diperoleh dari batuan induk atau source rock berupa serpih yang terperangkap dalam batuan induk itu sendiri. Shale gas merupakan salah satu gas non-konvensional yang memiliki potensi dua kali lebih besar dari gas konvensional dengan nilai 500 BCFD.

Cekungan Kutai merupakan cekungan tersier tertua yang dan terdalam di Indonesia bagian barat. Cekungan Kutai terdapat di timur kalimantan. Luasnya 
mencapai $165.000 \mathrm{~km}$ persegi dan kedalamannya 12.000-14.000 meter. Cekungan Kutai mempunyai potensi sumber daya energi yang cukup besar, seperti minyak dan gas bumi dan juga batubara. Courteney [2] dan Pertamina BPPKA [3] menyebutkan bahwa Cekungan Kutai merupakan cekungan tersier penghasil minyak dan gas terbesar kedua di Indonesia setelah Cekungan Sumatera Tengah, yaitu dengan cadangan terbukti lebih dari 11 BBOE (billion barrel oil equivalent).

Metode Magnetotelurik digunakan dalam penelitian ini dikarenakan keterbatasan penetrasi kedalaman oleh metode Seismik. Hal ini disebabkan oleh batugamping yang sangat tebal sebagai low velocity layer, sehingga sulit bagi gelombang mekanik untuk menembus lapisan tersebut. Metode ini memanfaatkan penjalaran gelombang elektromagnetik dengan penetrasi kedalaman yang tinggi sehingga mampu merepresentasikan kondisi bawah permukaan khususnya Organic Shale pada Cekungan Kutai berdasarkan nilai tahanan jenisnya. Metode MT efektif untuk mendeliniasi lapisan yang konduktif dibandingkan untuk mengidentifikasi lapisan yang resistif [4]. Diperolehnya kontras nilai tahanan jenis, maka keberadaan Organic Shale dapat dimodelkan dengan baik.

Tujuan peneliti ini adalah memodelkan organic shale yang paling baik dengan melakukan baik dengan melakukan pengolahan data dan interpretasi data MT. Pengolahan data MT di Cekungan Kutai menggunakan software SSMT2000, MTEDITOR dan WINGLINK. Tahapan ini dimulai dari konversi TS ke FT (robust processing), picking data dari setiap frekuensi sehingga didapatkan tren data yang benar kemudian dilanjutkan dengan pembuatan peta resistivitas untuk dilakukan interpretasi persebaran organic shale disetiap kedalaman yang telah ditentukan.

\section{Lokasi dan Geologi}

Cekungan Kutai merupakan salah satu cekungan di Indonesia yang menutupi daerah seluas $\pm 60.000 \mathrm{~km} 2$ dan mengandung endapan berumur Tersier dengan ketebalan mencapai 14 $\mathrm{km}$. Cekungan ini merupakan cekungan terbesar dan terdalam di Indonesia Bagian Timur. Cekungan Kutai terletak di tepi bagian timur dari Paparan Sunda, yang dihasilkan sebagai akibat dari gaya ekstensi di bagian selatan Lempeng Eurasia.

Cekungan dibatasi di bagian utara oleh suatu daerah tinggian batuan dasar yang terjadi pada Oligosen [5], yaitu Tinggian Mangkalihat dan Sesar Sangkulirang yang memisahkannya dengan Cekungan Tarakan. Di bagian timur daerah cekungan ini, terdapat Delta Mahakam yang terbuka ke Selat 
Makasar. Di bagian barat, cekungan dibatasi oleh daerah Tinggian Kuching (Central Kalimantan Ranges) yang berumur Kapur [5]. Di bagian tenggara cekungan ini, terdapat Paparan Paternoster yang dipisahkan oleh gugusan Pegunungan Meratus. Di bagian selatan cekungan ini, dijumpai Cekungan Barito yang dipisahkan oleh Sesar Adang.

Struktur tektonik yang berkembang pada Cekungan Kutai berarah timur laut-barat daya (NE-SW) yang dibentuk oleh Antiklinorium Samarinda, yang berada di bagian Timur - Tenggara cekungan [6]. Antiklinorium Samarinda tersebut memiliki karakteristik terlipat kuat, antiklin asimetris dan dibatasi oleh sinklin-sinklin yang terisi oleh sedimen silisiklastik Miosen [7].
Teori mengenai asal terbentuknya struktur-struktur pada Cekungan Kutai masih dalam perdebatan. Beberapa peneliti mengajukan teori seperti vertical diapirism, gravitational gliding [8], inversion trough regional wrenching [8], micro-continental collision, detachment folding above overpressured sediments [5] dan differential loading on deltaic sedimen and inverted delta growth fault system [9].

Menurut Allen dan Chambers [10], Cekungan Kutai tersusun atas endapan-endapan sedimen berumur Tersier yang memperlihatkan endapan fase transgresi dan regresi laut, yaitu: Pertama, Fase Transgresi Paleogen Fasa sedimentasi Paleogen dimulai ketika terjadi fasa tektonik ekstensional dan pengisian rift pada kala Eosen.

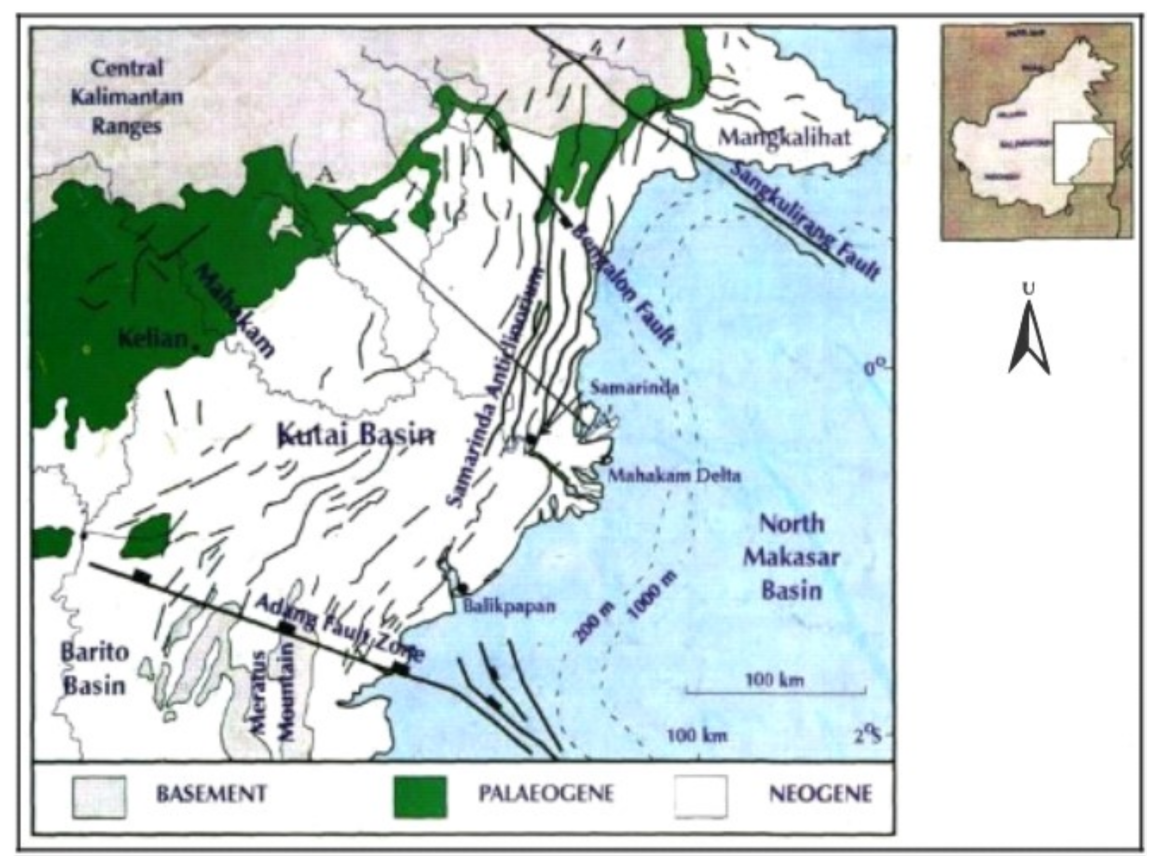

Gambar 1. Struktur geologi Cekungan Kutai 
Pada masa ini, Cekungan Barito, Kutai, dan Tarakan merupakan zona subsidence yang saling terhubungkan [5], kemudian sedimentasi Paleogen mencapai puncak pada fasa pengisian pada saat cekungan tidak mengalami pergerakan yang signifikan, sehingga mengendapkan serpih laut dalam secara regional dan batuan karbonat pada Oligosen Akhir. Kedua, Fase Regresi Neogen Fase ini dimulai pada Miosen Awal hingga sekarang, yang menghasilkan progradasi delta (deltaic progradation) yang masih berlanjut hingga sekarang. Sedimen regresi ini terdiri dari lapisan-lapisan sedimen klastik delta hingga laut dangkal dengan progradasi dari barat kearah timur dan banyak dijumpai lapisan batubara (lignite).

Berdasarkan Peta Geologi Lembar Samarinda [6], stratigrafi Cekungan Kutai dibagi menjadi (dari tua ke muda): Formasi Pamaluan, Formasi Bebuluh, Formasi Pulau Balang, Formasi Balikpapan, Formasi Kampung Baru.

\section{Konsep Dasar}

Metode elektromagnetik adalah metode geofisika yang memanfaatkan gelombang elektromagnetik yang merupakan gabungan antara medan listrik dan medan magnet yang berubah terhadap waktu.
Keberadaan medan listrik selalu disertai keberadaan medan magnet, dan begitu pula sebaliknya. Fenomena gelombang elektromagnetik dapat dijelaskan melalui teori Maxwell.

$$
\nabla \times \vec{E}=-\frac{\partial \vec{B}}{\partial t}
$$

(Hukum Faraday)

$$
\nabla \times \vec{H}=j+\frac{\partial \vec{D}}{\partial t}
$$

(Hukum Ampere)

$$
\nabla \cdot \vec{B}=0
$$

(Hukum Coloumb)

$$
\nabla \cdot \vec{D}=\rho
$$

(Hukum Fluks Magnet)

$$
\begin{array}{cl}
\begin{array}{c}
\text { dengan } \\
\vec{E}
\end{array} & \\
\vec{H} & : \text { medan listrik (Volt } / \mathrm{m}) \\
\vec{B} & : \text { fluks atau induksi magnetik } \\
& \text { (Weber/m2 atau Tesla) } \\
\mathrm{j} & : \text { rapat arus (Ampere/ m2) } \\
\rho & : \text { densitas muatan listrik } \\
& (\mathrm{C} / \mathrm{m} 3)
\end{array}
$$

Pada medium homogen dan isotropis berlaku hubungan :

$$
\begin{aligned}
& j=\sigma \cdot \vec{E} \\
& \vec{D}=\varepsilon \cdot \vec{E}
\end{aligned}
$$


Pada medium homogen dan isotropis berlaku hubungan :

$$
\begin{aligned}
& j=\sigma \cdot \vec{E} \\
& \vec{D}=\varepsilon \cdot \vec{E} \\
& \vec{B}=\mu \cdot \vec{H}
\end{aligned}
$$

dengan

$\mu$ : permeablititas magnetik (Henry/m)

$\sigma$ : konduktivitas (Ohm-1/m atau siemen/ $\mathrm{m})$

$\varepsilon:$ permitivitas listrik (Farad $/ \mathrm{m})$

Variabel medan listrik dan medan magnet di atas dapat dipisahkan dengan operasi curl sehingga didapatkan

$$
\begin{aligned}
\nabla^{2} \vec{E} & =i \omega \mu \sigma \vec{E}-\omega^{2} \varepsilon \mu \vec{E} \\
\nabla^{2} \vec{H} & =i \omega \mu \sigma \vec{H}-\omega^{2} \varepsilon \mu \vec{H}
\end{aligned}
$$

Suku pertama dan suku kedua pada ruas kanan berhubungan dengan konduksi dan perpindahan arus. Persamaan di atas adalah persamaan medan elektromagnetik untuk penjalaran vektor medan dan medan listrik dalam medium homogen isotropik dengan konduktivitas $\sigma(\mathrm{S} / \mathrm{m})$, permeabilitas magnetik $\mu(\mathrm{H} / \mathrm{m})$, dan kapasitas dielektrik $\varepsilon(\mathrm{F} / \mathrm{m})$.

Dalam kasus dua dimensi, persamaan Maxwell untuk gelombang elektromagnetik terbagi atas dua bentuk mode polarisasi. Pertama sebagai TE-mode (E-polarisasi) dimana satu medan listrik (Ex) sejajar terhadap arah strike di sepanjang sumbu $\mathrm{x}$ dan dua medan magnet (Hy dan $\mathrm{Hz}$ ) berada dalam bidang Y-Z. Kedua, TM-mode (Hpolarisasi) dimana satu medan magnet (Hx) sejajar arah strike di sepanjang sumbu $x$ dan dua medan listrik (Ey dan Ez) dalam bidang Y-Z.

Dalam suatu frekuensi tertentu perubahan sinusoidal amplitudo kuat medan magnet dan kuat medan listrik pada dua arah yang saling tegak lurus dalam selang waktu yang singkat adalah $\Delta \mathrm{Hx}(\mathrm{nT})$ dan $\Delta \mathrm{Ey}(\mathrm{mV} / \mathrm{km})$ dengan mengasumsikan bumi uniform dan hasil penurunan lebih lanjut teori Maxwell diperoleh hubungan antara tahanan jenis $(\rho)$, kuat medan listrik (E), kuat medan magnet $(\mathrm{H})$ dan frekuensi (f) sebagai berikut :

$$
\rho=0.2 T\left|\frac{\Delta E_{x}}{\Delta H_{y}}\right|^{2}
$$

Jika bumi tidak homogen, maka persamaan (2.10) mendefinisikan tahanan jenis semu $\rho_{a}$.

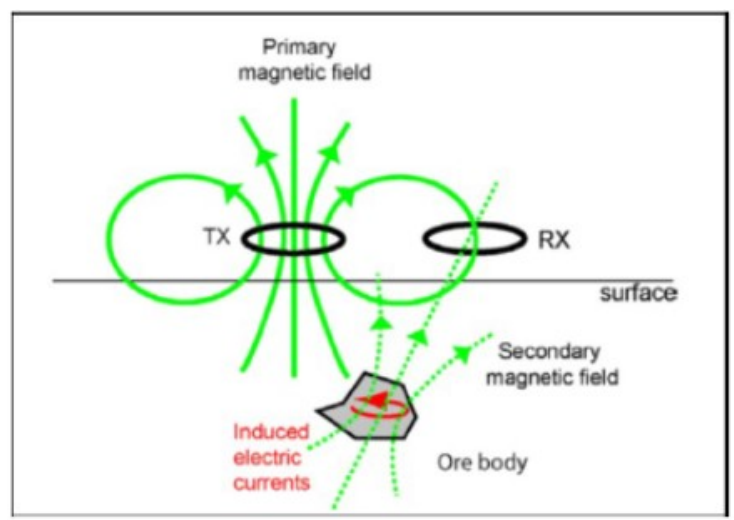

Gambar 2. Konsep penjalaran gelombang elektromagnetik [11] 


\section{Metode}

MT merupakan metode elektromagnetik yang mengukur variasi medan elektromagnetik yang terjadi di alam sebagai sumbernya [12]. Pada dasarnya, metode magnetotellurik mengukur variasi medan listrik $\vec{E}$ dan medan magnet $\vec{H}$ secara tegak lurus di permukaan bumi yang berubah terhadap waktu, untuk mengetahui variasi nilai resistivitas bawah permukaan bumi. Besarnya frekuensi medan elektromagnetik alam berkisar antara 10-4 hingga $104 \mathrm{~Hz}$ [13]. Frekuensi tersebut berpengaruh terhadap penetrasi kedalaman gelombang, semakin rendah frekuensi medan elektromagnetik maka penetrasi kedalaman yang dicapai akan semakin besar. Sedangkan pada frekuensi tinggi, penetrasi kedalaman gelombang akan semakin kecil. Selain itu, pada medium yang lebih konduktif, maka penetrasi kedalaman akan semakin rendah dibandingkan dengan medium yang lebih resistif.

Penelitian identifikasi keberadaan organic shale dengan data MT dapat digambarkan dalam diagram alir gambar 3 . Format data yang didapatkan setelah akuisisi adalah file header yang berisi informasi lapangan seperti waktu pengukuran, koordinat dan lain sebagainya juga berisi data time series frekuensi rendah hingga frekuensi tinggi. Data time series merupakan salah satu data awal hasil series merupakan salah satu data awal hasil dari pengukuran Magnetotelluric yang merepresentasikan fluktuasi medan magnet dan medan listrik dalam domain waktu, dalam hal ini perlu dilakukan konversi dari domain waktu ke domain frekuensi. Proses pengubahan time series ke fourier transform dimana penentuan parameter transformasi fourier meliputi input data type, output data format, band, processing times. Data yang digunakan adalah data lapangan maka input data type yang digunakan adalah measured field. Pengolahan selebihnya menggunakan deafault setting dari aplikasi yang tersedia.

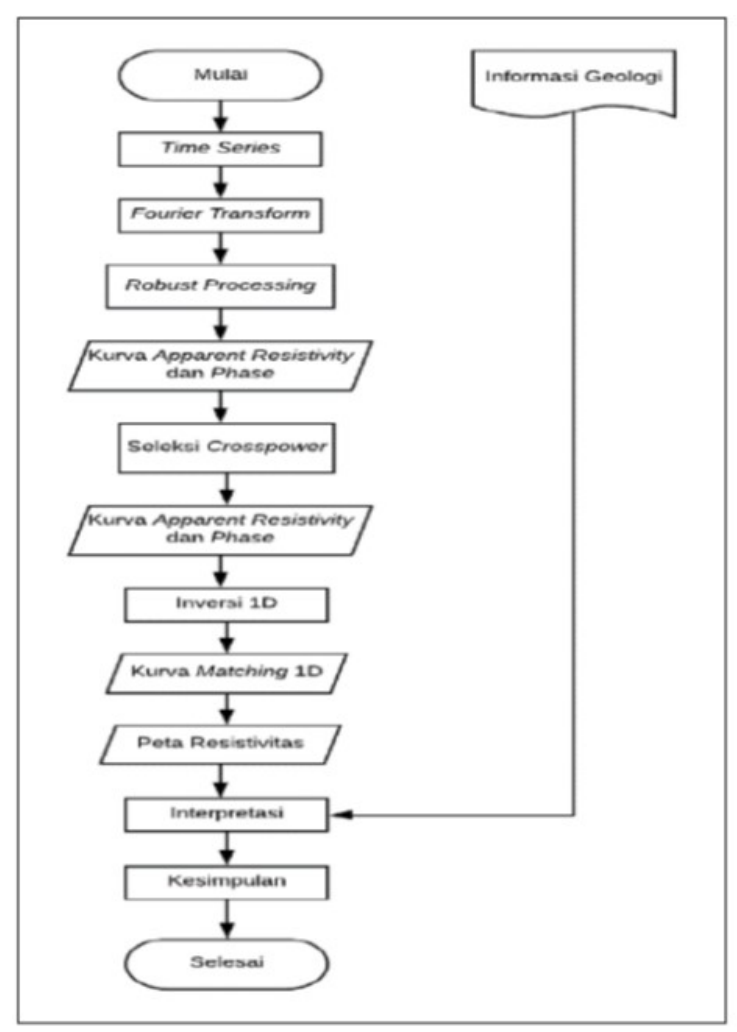

Gambar 3. Diagram Alir Penelitian 
Sebelum dilakukannya robust processing terdapat beberapa parameter dalam processing yang perlu dilakukan pengaturan. Pertama select reference type, pengaturan ini bergantung pada proses akuisisi, pada pengolahan ini digunakan akuisisi single station sehingga reference type yang digunakan adalah Local $H$. Namun apabila pengukuran dilakukan menggunakan 2 alat atau lebih pada waktu yang bersamaan maka digunakan Remote $H$. Setelah dilakukan proses robust processing maka akan didapatkan kurva apparent resistivity dan fasa yang belum dilakukan seleksi crosspower terhadap data tersebut.

Pada seleksi crosspower dilakukan muting data yang menyimpang dari tren kurva yang dianggap sebagai noise. Muting data ini dilakukan menggunakan software Mteditor guna meningkatkan nilai koherensi data. Kemudian, didapatkan kembali kurva apparent resistivity dan fasa yang telah dilakukan muting data sehingga didapatkan data dengan nilai koherensi yang lebih tinggi.

Proses inversi yang dilakukan menggunakan software WinGLink. Tahap pertama sebelum melakukan proses inversi adalah membuat peta elevasi dan plotting titik pengukuran MT. Selanjutnya, dilakukan penyesuaian antara kurva apparent resistivity dan phase impedance titik sounding dengan kurva smoothing $\mathrm{D}+$ curve dengan rho error 5\% dan phase error 5\%. Proses selanjutnya merupakan proses membuat peta resistivitas disetiap kedalaman yang telah ditentukan menggunakan software WinGLink dengan tujuan dapat mengetahui persebaran daripada target yaitu organic shale bedasarkan nilai resistivitas. Persebaran mencakup kedalaman daripada target berdasarkan persebaran nilai resistivitas. Berikut tampilan pembuatan peta menggunakan software WinGLink. Kemudian, dilakukan interpretasi sesuai dengan target yang diinginkan dan disesuaikan dengan geologi daerah penelitian.

\section{Hasil dan Pembahasan}

Gambar 4 menampilkan peta resistivitas pada kedalaman 500, 1500, 2500, 3500, 4500, 5500, 6500, 7500, 8500, 9500 hingga 10500 hasil dari sounding MT pada 18 titik di cekungan Kutai. Organic Content seperti yang kita ketahui memiliki nilai resistivitas yang besar, namun pada kasus ini Organic Shale memiliki nilai konduktivitas yang sangat tinggi / nilai resistivitas yang sangat rendah. Hal tersebut dipengaruhi oleh thermal maturity yang merubah susunan dan ikatan kimia organic content tersebut [14].

Organic Shale merupakan penyebab untuk sejumlah anomali resistivitas rendah yang ditemukan di kerak bumi bagian atas $[15,16,17]$. Resistivitas rendah 
dalam organic shale juga terkait dengan pematangan termal yang tinggi $\left(>400^{\circ} \mathrm{C}\right)$ [18]. Peningkatan suhu menyebabkan perubahan komposisi kimia karbon organik yang ditemukan pada butir organic shale, yang akibatnya mengubahnya menjadi fase konduksi listrik [19]. Baru-baru ini, sebuah studi [20] menggambarkan organic shale Whitehill di Afrika Selatan sebagai lapisan lateral luas dengan resistivitas listrik yang sangat rendah yang dapat dipetakan sepanjang ratusan kilometer. Melengkapi studi ini, pengukuran menegaskan laboratorium juga dilakukan pada sampel batu serpih hitam Whitehill dan menegaskan bahwa resistivitas listrik yang lebih rendah terkait dengan sampel yang telah terkena suhu yang lebih tinggi [21].

Peta tersebut menunjukkan persebaran nilai resistivitas dimana nilai resistivitas yang sangat rendah $(<5$ ohm.m) berwarna ungu diinterpretasikan sebagai organic shale. Jelas tampak pada peta bahwa proses pematangan thermal organic content yang terkandung dalam shale mulai terjadi pada kedalaman 2500 hingga 9500 dan persebarannya relatif kearah barat daya - timur laut. Keberadaan organic shale diprediksi berada pada formasi pamaluan.

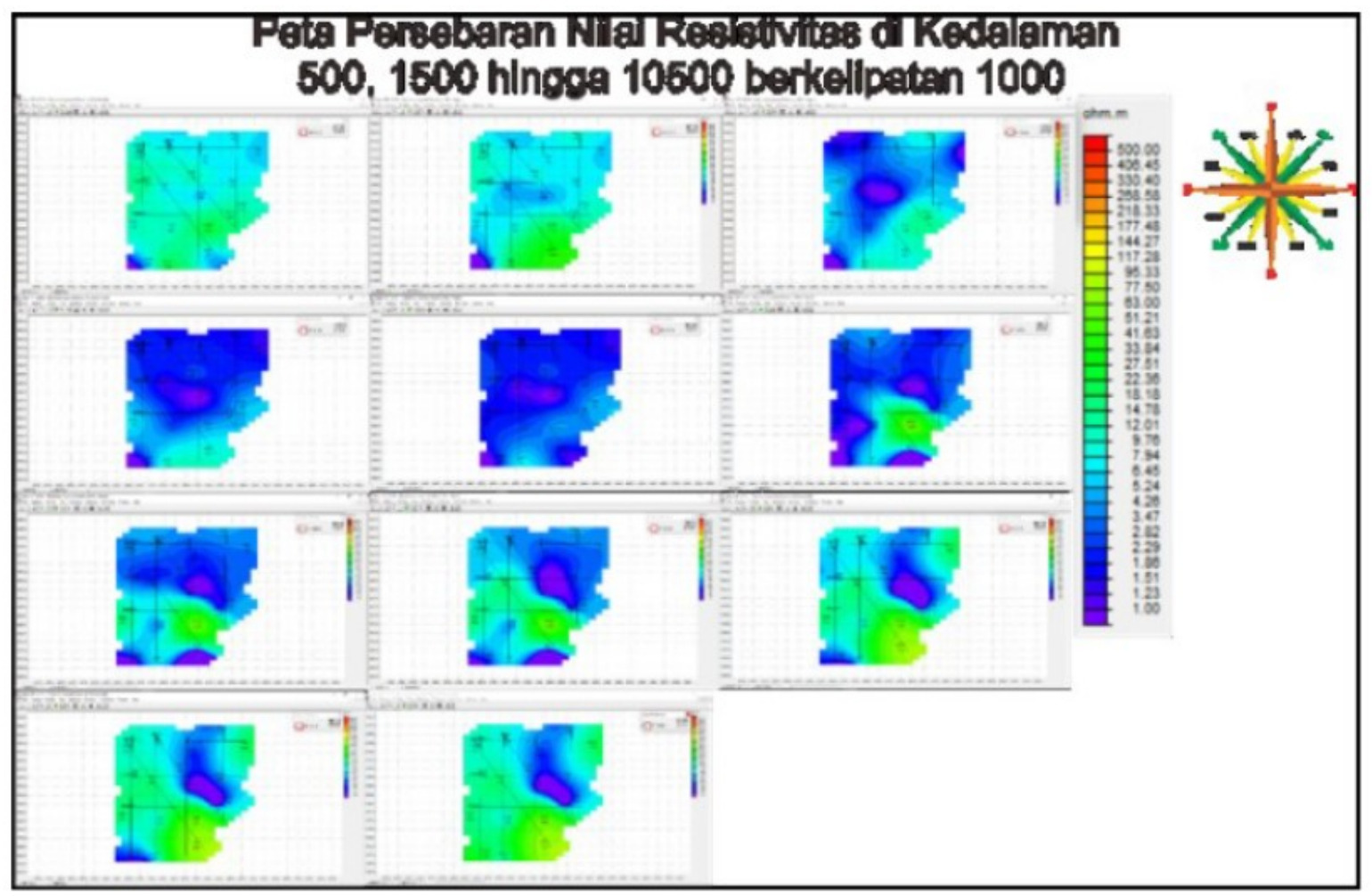

Gambar 4. Peta persebaran nilai resistivitas di kedalaman yang telah ditentukan 
Secara umum, Formasi Pamaluan diwakili oleh mudstone dan batuserpih berwarna abu-abu muda sampai hitam yang mengandung sisa-sisa tumbuhan karbon. Pamaluan bagian bawah terdiri dari batubatuan siltstones dan batulempung dengan batupasir yang sangat halus. Formasi Pamaluan atas secara dominan tersusun atas batulumpur dengan fraktur konkoidal, atau lapisan batuserpih berlapis, yang seringkali mengandung sisa -sisa tumbuhan karbon. Batu pasir dan perlapisan batu bara juga ditemukan dan batu kapur tipis tampak pada bagian atas formasi [22]. Pada kedalaman 10500 meter belum dapat diinterpretasikan sebagai organic shale dikarenakan proses crosspower hanya sampai dengan frekuensi 0,01 Hz.

\section{Kesimpulan}

Berdasarkan hasil pengolahan data dan analisis, dapat ditarik kesimpulan bahwa peta persebaran nilai resistivitas disetiap kedalaman dapat membantu mendeliniasi pengolahan dalam menentukan sayatan untuk pengolahan lebih lanjut seperti 2D, 3D juga integrasi dengan metode lain. Resistivitas rendah diinterpretasikan sebagai organic shale dan kedalaman mempengaruhi proses pematangan organic content dimana hal tersebut dapat digambarkan oleh nilai resistivitas pada peta.

\section{Referensi}

1. Purnomo, 2014. Ketahanan Energi Nasional 2014. Jakarta : Dewan Energi Nasional.

2. Courteney S. 1991. Indonesia oil and gas fields atlas. 1988;5.

3. Pertamina, B. P. P. K. A. (1997). Petroleum geology of Indonesian basins. Principles Methods and Application. Vol. 10. South Sumatra Basins, 1-85.

4. Wameyo, P. M. (2005). Magnetotelluric And Transient Electromagnetic Methods In Geothermal Prospecting. With Examples From Menengai, Kenya The United Nation University Geothermal Training Programme Report, 21, 416.

5. Chambers, John L.C., Moss, Steve J. 2000. Depositional Modeling and Facies Architecture of Rift and Inversion Episodes in The Kutai Basin, Kalimantan Indonesia. Proceeding of the Fourth Annual Convention, XXVII, Indonesian Petroleum Association, 467-486, Jakarta.

6. Supriatna, S., Sudrajat, A., Abidin, H.Z., 1995. Geological Map of the Muara Tewe Quadrangle, Kalimantan, Geological Research and Development Centre, Bandung.

7. Satyana, A.H., Nugroho, D., Surontoko, I., 1999, Tectonic Controls On The Hydrocarbon Habitats of The 
Barito, Kutai And Tarakan Basin, Eastn Kalimantan, Indonesia, Journal Of Asian Earth Sciences Special Issue Volume 17, hal 99 - 122.

8. Satyana, A. H., \& Biantoro, E. (1996). Seismic stratigraphy of Eocene Beriun sands of West Bungalun, East Kalimantan, Indonesia: a contribution to the Paleogene stratigraphical knowledge of the Kutei Basin.

9. Paterson, D.W., Bachtiar, A., Bates, J.A., Moon, J.A., Surdam, R.C., 1997. Petroleum System of the Kutai Basin, Kalimantan, Indonesia, Petroleum System of SE Asia Australia Conference, May 1997. Proceedings Indonesia Petroleum Association, Jakarta., p:711-713

10. Allen, G.P., Chambers, John L.C. 1998. Sedimentation of The Modern and Miocene Mahakam Delta. Indonesian Petroleum Assosiation, Jakarta.

11. Unsworth, Martyn. 2014. Theory of electromagnetic (EM) field propagation in the Earth. Alberta: University of Alberta.

12. Tikhonov, A. N., 1950. On determining electrical characteristics of the deep layers of the Earth's crust. Dok. Akad. Nauk., USSR, 73(2), 295-297.

13. Vozoff, K. 1990. Magnetotellurics: Principles and practice. Earth
Planet. Sci., 99, 441-471.

14. Adao, F., Ritter, O. \& Spangenberg, E. 2015. The electrical resistivity of Posidonia black shale - from magnetotelluric exploration to rock samples. Geophysical Prospecting, Accepted.

15. Gaucher, E. (1983). Estimation of Sulfide Content of a Potential Orebody from Surface Observations and its Role in Optimising Explorations Programmes. A. A. Fitch (ed.), Developments in Geophysical Exploration Methods, 4

16. Loukola-Ruskeeniemi, K. (1989). Early Proterozoic Metamorphosed Black Shales in the Kainuu Schist Belt and in the Outokumpu Region. Geological Survey of Finland, 10 (Special Paper), 103-106.

17. Gaucher, E. (1983). Estimation of Sulfide Content of a Potential Orebody from Surface Observations and its Role in Optimising Explorations Programmes. A. A. Fitch (ed.), Developments in Geophysical Exploration Methods, 4

18. Duba, A. (1983). Electrical conductivity of Colorado oil shale to $900^{\circ}$ C. Fuel, 62, 966- 972.

19. Jödicke. (1992). Water and graphite in the Earth's crust: An approach to interpretation of conductivity model. Surv. Geophys., 13, 381-407.

20. Weckmann, U., Jung, A., Branch, 
T. \& Ritter, O. (2007b). Comparison of electrical conductivity structures and 2D magnetic modelling along two profiles crossing the Beattie magnetic anomaly. South African Journal of Geology, 110, 449-464.

21. Branch, T., Ritter, O., Weckmann, U., Sachsenhofer, R. \& Schilling, F. (2007). The Whitehill formation: a high conductivity marker in the Karoo Basin. South. Afr. J. Geol., 110, 465-476

22. Leupold, w. \& Van Der Vlerk, 1931. The Tertiary. In Festbundel K. Martin, Leidsche Geol. Meded., v.5, pt.3, 611-650. 